\title{
Timing of gluten introduction and quantity and nature of gluten-containing foods consumed by infants in Valencia, Spain
}

\author{
B. Soto, A. López and C. Ribes \\ Pediatric Gastroenterology and Hepatology Section, La Fe Hospital, Valencia, Spain
}

Currently, there is no information on the level of gluten intake for Spanish children. Recent studies have shown that the timing of gluten introduction in relation to breast-feeding as well as the amount of gluten could be related to a higher incidence of coeliac disease ${ }^{(1,2)}$. The food questionnaire estimates how frequently certain foods are eaten in a specific period of time. The aim of the present study was to develop and validate a food questionnaire for the assessment of gluten consumption of children aged 3-12 months in the Valencia area.

Information on the gluten-containing food intake of healthy children aged 3-12 months was collected prospectively, including the brand names. For the study the children were assigned to two groups: 3-6 months; 7-12 months. Information was compiled by interviewing parents to establish how and when foods other than breast milk or formula milk were introduced into their children's diet. The mostfrequently-used gluten-containing food products were selected and included in the FFQ, which covered a period of $7 \mathrm{~d}$. To calculate the amount of gluten in these products the vegetable protein content was multiplied by $0.8^{(3)}$. To validate the FFQ the results of this FFQ were compared with those from a $7 \mathrm{~d}$ food record ${ }^{(4)}$. If gluten had been introduced before the study was conducted, the exact timing of introduction was recorded.

A total of 100 children were included in the study. In the age-category 3-6 months none of the thirty babies had started consuming gluten. Moreover, when asked about the timing of gluten introduction the thirty mothers with children aged between 7 and 24 months all reported that gluten had been introduced after the sixth month of life.

\begin{tabular}{lcccc}
\hline Age (Months) & $<7$ & $7-8$ & $8-9$ & $>9$ \\
\hline$\%$ children consuming gluten & 0 & 60 & 70 & 100 \\
\hline
\end{tabular}

In the 7-12 months age-group ( $n$ 70) the most important gluten-containing food products consumed were muffins and croissants, cereals, chocolate, ready-to-eat fruit and ready-to-eat meals, biscuits, bread, pasta (macaroni, spaghetti etc.) and crumbed products. All children $>9$ months were consuming gluten-containing food products. In a preliminary study of the gluten intake in this group the mean gluten intake obtained from the FFQ was $2.55 \mathrm{mg} / \mathrm{d}$.

The current amount of gluten consumed by children in Spain, and more specifically in Valencia, has been established. The variety of gluten-containing food is limited and controlled, and the mean daily gluten intake in this preliminary study is $2.55 \mathrm{mg} / \mathrm{d}$. Moreover, the timing of gluten introduction for infants in Valencia is between 7 and 9 months of age. It has been shown previously that gluten introduction after 7 months of age in at-risk infants is associated with a higher risk of coeliac disease, i.e. 1.87 as compared with gluten introduction between 4 and 6 months (OD 1) $)^{(2)}$. It is possible that this late introduction of gluten could be related to the higher prevalence of coeliac disease observed in the Valencia area in the last 5 years.

1. Ivarsson A, Persson LA, Nyström L et al. (2000) Acta Paediatr 89, 165-171.

2. Norris JM, Barriga K \& Hoffenberg EJ (2005) JAMA 293, 2343-2351.

3. Overbeek FM, Uil-Dieterman IG, Mol IW, Köhler-Brands L, Heymans HS \& Mulder CJ (1997) Eur J Gastroenterol Hepatol 9, $1097-1099$.

4. Hopman EG, Kiefte-de Jong JC, le Cessie S, Moll H, Witteman J, Bleeker S \& Mearin M (2007) Clin Nutr 26, 264-271. 